\title{
Application of qualitative tests for detection of adulterants in pasteurized milk and during its subsequent storage
}

\author{
KD Aparnathi, Arpita Agnihotri, MP Chauhan, AI Shaikh and SI Patel
}

Received: 27 January 2019 / Accepted: 08 April 2019 / Published online: 22 June 2019

(C) Indian Dairy Association (India) 2019

\begin{abstract}
Effect of widely used heat treatments of milk on performance of selected qualitative tests for detection of common adulterants in the milk was carried out. Genuine and adulterated samples of milk were heated to $72^{\circ} \mathrm{C}$ for $16 \mathrm{sec}$ for pasteurization. The samples of pasteurized milk were stored at temperature of $5 \pm 1^{\circ} \mathrm{C}$. The qualitative tests were performed for detection of adulterants at an interval of $24 \mathrm{~h}$. The performance of the qualitative tests varied depending on type of heat treatment employed in processing of milk, length of storage period for which samples were stored and chemical nature of the target adulterant spiked in the milk.
\end{abstract}

Keywords: Adulteration, Milk, Pasteurization, Qualitative tests

\section{Introduction}

Milk and milk products are frequently included as important elements in a healthy and balanced diet (Pereira, 2013). Adulteration of milk and milk products has become global

KD Aparnathi, Arpita Agnihotri, MP Chauhan, AI Shaikh ( $₫)$ and SI Patel

Dairy Chemistry Department, SMC College of Dairy Science. Anand Agricultural University, Anand (India)

Email: ahesanss@gmail.com, Mobile:+919427382800 concern; specifically for developing countries (Handford et al. 2015; Azad and Ahmed, 2016; Roy et al.2017). Adulteration of milk with various harmful chemicals can have serious consequences on human health (Bhatt et al.2008, Handford et al. 2015, Roy et al. 2017). For detection of adulterants in milk qualitative tests based on chemical reactions possesses better specificity. Moreover, they are simple, cheap and easy to perform as a rapid platform test (Roy and Mittal, 1977; Chakraborti and Raghav, 2000). Further, qualitative tests are applied for the analysis of milk and their products by dairy industry to check compliance with quality requirements, particularly regards freedom from adulteration (Souza et al. 2011). Pasteurization is one of the most common processing operation to which milk is subjected. Adulterants are chemical substances which may undergo certain transformations (adsorption, degradation, isomerization, complexation, etc.) upon heat processing of milk. Moreover, storage of milk after processing may enhance the transformations of the adulterants. Such transformations of the adulterant may alter the performance of qualitative tests suggested for detection of these adulterants in milk.. In the present study, effect of pasteurization of milk and subsequent storage on the efficacy of commonly used adulteration detection methods have been studied.

\section{Materials and methods}

\section{Authentic milk samples}

Milk samples were procured from animal farms of the Anand Agricultural University, Anand. Raw pooled milk samples were collected from the herd.

\section{Chemicals and reagents}

Chemicals and reagents used were p-dimethyl aminobenzaldehyde (DMAB), Trichloroacetic acid (TCA), Iodine, Maltodextrin (LobaChemie (P) Ltd., Mumbai); Bromothymol blue, Sodium hydroxide, Formalin and Hydrogen peroxide (Qualigens Fine Chemicals Ltd., Mumbai); Sodium hypochlorite and Urea (SD Fine Chemicals Ltd., Mumbai); Mercuric chloride (Sarabhai Chemicals (P) Ltd., Ahmedabad); Methylene blue (Merck Specialities (P) Ltd., Mumbai); p-phenylenediamine (Fisher 
Scientific, Mumbai); Rosolic acid (Spectrochem(P) Ltd., Mumbai); Ammonium sulphate (BDH Laboratory, Mumbai) Labolene (detergent) (Himedia Laboratories (P) Ltd., Mumbai).

\section{Selection of adulterants for the study}

The adulterants commonly referred in the literature and likely to be affected by heat processing were selected for study and listed in Table 1.

\section{Adulterated milk samples}

Adulterated samples of milk were prepared by spiking individual adulterant at the rate of 1.25 times the limits of their detection (LoD), established in this laboratory (unpublished work). The rate at which each adulterant spiked in milk is presented in Table 1.

\section{Strategy to evaluate effect of heat processing on performance of the qualitative tests}

For evaluating the effect of treatments of milk on the performance of the selected qualitative tests in detection of adulterants in milk the following processing operation, four types of samples were prepared.

(1) Negative control - a genuine raw milk without adulterant and without any processing

(2) Positive control - an adulterated raw milk containing target adulterant

(3) Negative test sample - a genuine pasteurized milk

(3) Positive test sample - an adulterated pasteurized milk containing target adulterant

\section{Selection of qualitative tests for detection of adulterants}

The qualitative test employed for detection of particular adulterant as target are given in Table 1. The procedure for performing the test were followed as reported for the respective test or after slight modification.

\section{Heat processing, storage and testing of milk}

Both genuine and adulterated milk were subjected to heat treatment at $72^{\circ} \mathrm{C}$ for $16 \mathrm{~s}$ in laboratory water bath followed by cooling to $5 \pm 1^{\circ} \mathrm{C}$. The genuine and adulterated samples of the pasteurized milk were filled in LDPE pouches and stored at $5 \pm 1^{\circ} \mathrm{C}$ in refrigerator.

\section{Testing of milk}

The respective qualitative tests were performed for detection of adulterants in samples of genuine and adulterated samples of the pasteurized milk when fresh $(0 \mathrm{~h})$ and also at $24^{\text {th }}, 48^{\text {th }}$ and $72^{\text {nd }} \mathrm{h}$ of the storage. The test results so obtained were interpreted as positive (+ve), negative (-ve) or doubtful (?).

\section{Results and discussion}

Detergent, urea, ammonium salt, maltodextrin, starch, glucose, sucrose, gelatin, formaldehyde, hydrogen peroxide and neutralizers were used as adulterant in the study. Similarly, among various heat treatments employed in processing of milk, pasteurization being most commonly used, was studied.

Results of the qualitative tests performed for detection of various adulterants viz. methylene blue test for detergent, DMAB test urea, phenol test for ammonium salts, iodine test for maltodextrin, iodine test for starch, Barfoed test for glucose, Seliwanoff test for sucrose, picric acid test for gelatin, iodometric test for hydrogen peroxide, Leach test for formaldehyde and Rosolic acid test for neutralizers in pasteurized milk and during its subsequent storage is depicted in figures $1,2,3,4,5,6,7,8,9,10$ and 11 respectively.

\section{Effect on methylene blue test for detection of detergent in milk}

Methylene blue is a cationic dye which forms complex with anionic detergents due to ion pair formation between them. The complex so formed preferentially gets distributed into the chloroform phase of a two-phase (aqueous-chloroform) system. The measurement of dye in the chloroform phase is the basis for detection/estimation of anionic detergent in milk (Pedraza et al. 2007).

It was evident from the results that the pasteurization had no effect on performance of the methylene blue test for detection of detergent, when applied to fresh samples of pasteurized milk. Similarly, subsequent storage of the pasteurized milk at $5 \pm 1^{\circ} \mathrm{C}$ for a period of $72 \mathrm{~h}$ had no significant effect on performance of the test. Thus, for detection of detergent methylene blue test may be successfully applied to fresh as well as pasteurized samples of milk stored at $5 \pm 1^{\circ} \mathrm{C}$ for a period of $72 \mathrm{~h}$.

\section{Effect on DMAB test for detection of urea in milk}

Urea in milk can be detected using p-dimethylaminobenzaldehyde (DMAB) solution. The method is based on formation of yellow complex by urea with DMAB in a low acidic solution at room temperature (Bector et al. 1998).

The results revealed that the pasteurization had no effect on performance of the DMAB test for detection of urea when applied to fresh samples of pasteurized milk. On storage of these milk samples at $5 \pm 1^{\circ} \mathrm{C}$ for a period of $72 \mathrm{~h}$ slight darkening of yellow colour was noticed in genuine sample of milk. However, variation in colour observed in genuine milk and adulterated milk was sufficiently large to make out the difference between the two samples. Thus, for detection of urea DMAB test may be 
Table 1 Qualitative tests used to detect adulterants in milk

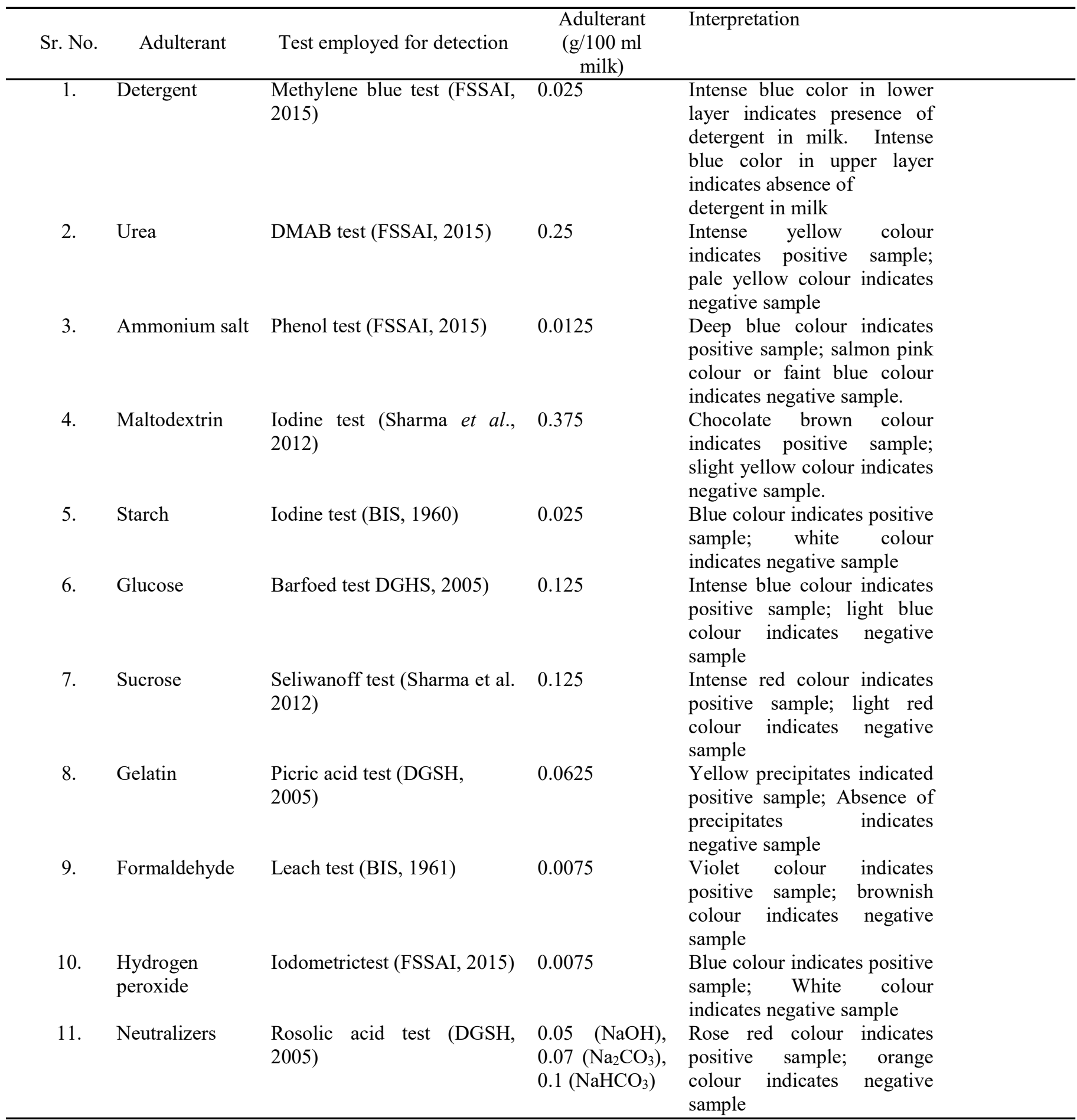

successfully applied to fresh samples of pasteurized milk as well as samples stored at $5 \pm 1^{\circ} \mathrm{C}$ for a period of $72 \mathrm{~h}$.

Effect on phenol test for detection of ammonium salts in milk
The ammonia-hypochlorite-phenol reaction is known for about 100 years as Berthelot reaction. Under suitable conditions reaction leads to the formation of an indophenol the colour of which is in proportion to amount of ammonia present in the sample (Kimble et al. 2006). 


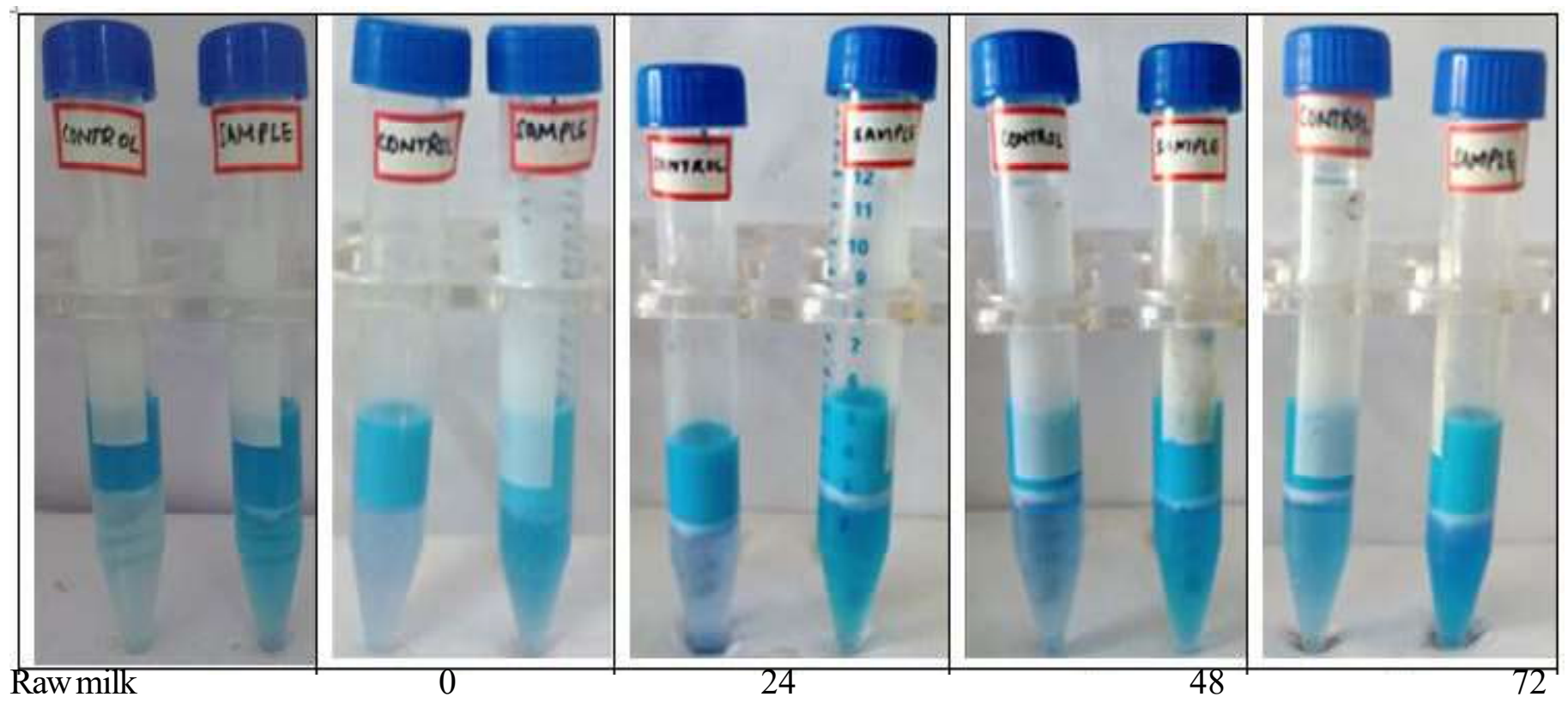

Fig. 1 Effect of pasteurization on methylene blue test for detection of detegent in milk

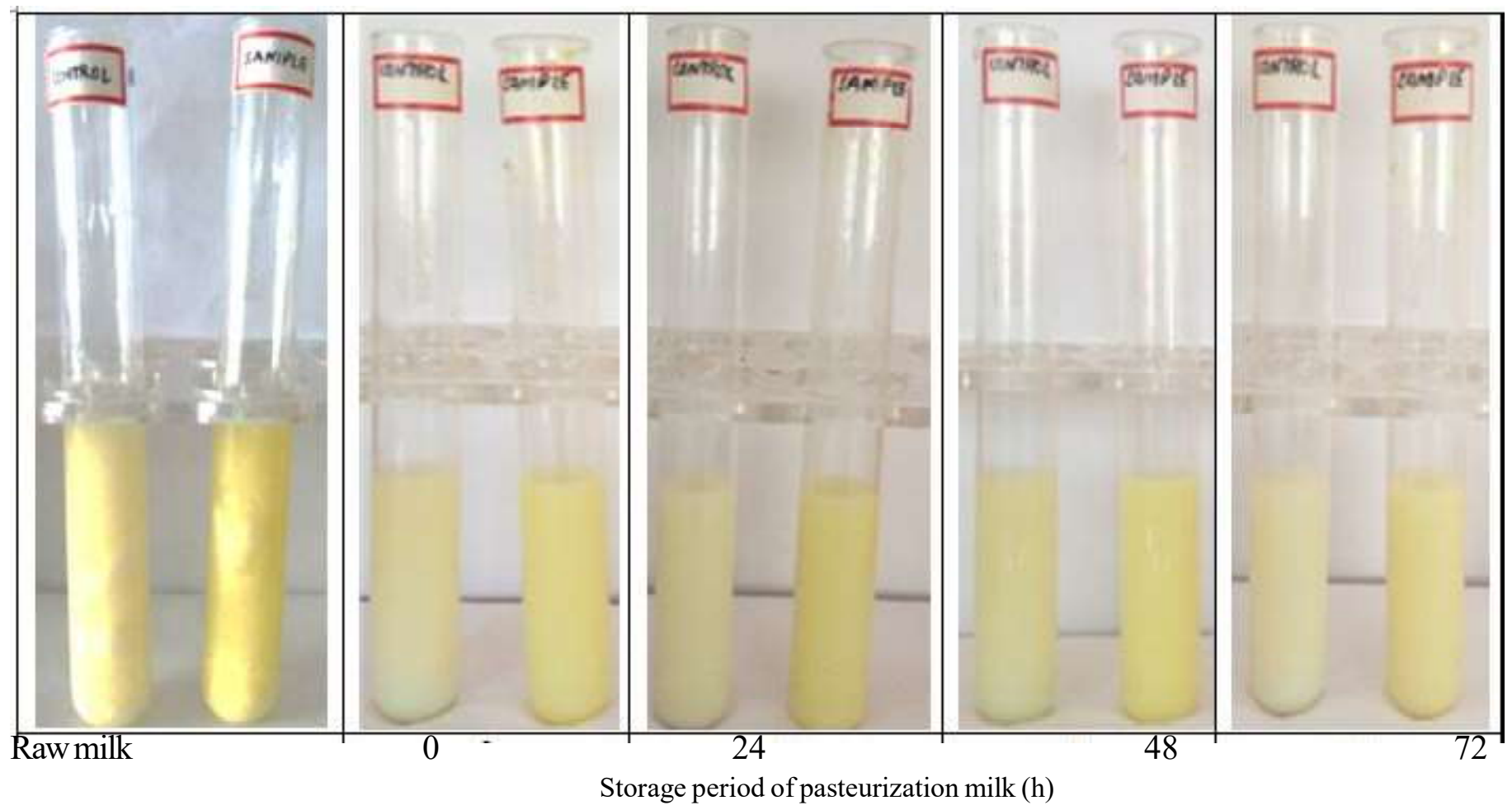

Fig.2 Effect of pasteurization on DMAB test for detection of urea in milk

From the outcome of the study it was noticed that pasteurization had no effect on performance of the phenol test for detection of ammonium salts when applied to fresh samples of pasteurized milk and also during its subsequent storage at $5 \pm 1{ }^{\circ} \mathrm{C}$ for a period of $72 \mathrm{~h}$, except slight darkening in genuine samples of milk. Thus, for detection of ammonium salt phenol test may be successfully applied to fresh samples of pasteurized milk as well as samples stored at $5 \pm 1^{\circ} \mathrm{C}$ for a period of $72 \mathrm{~h}$.

\section{Effect on iodine test for detection of maltodextrin in milk}




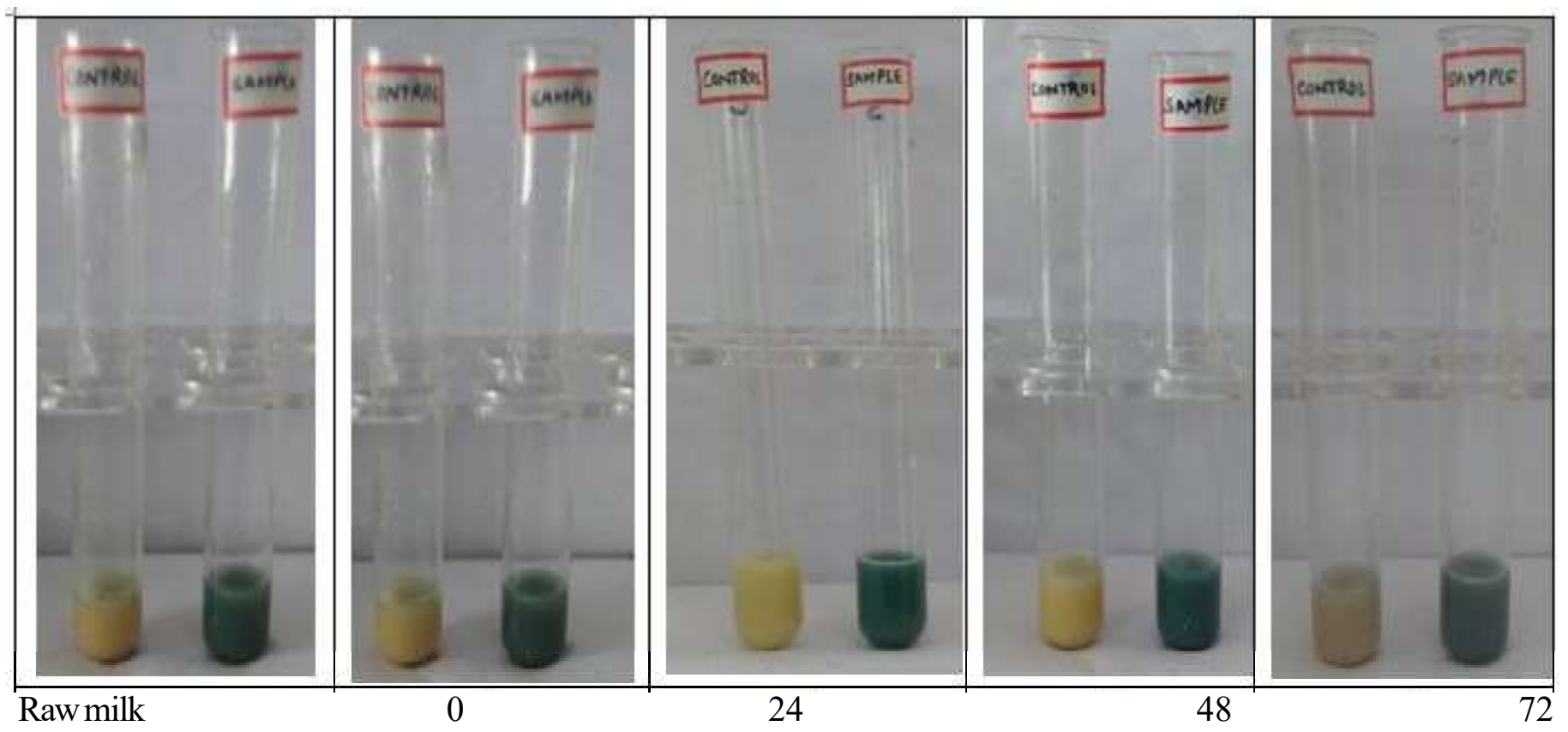

Storage period of pasteurization milk (h)

Fig. 3 Effect of pasteurization on phenol test for detection of ammonium sulphate in milk

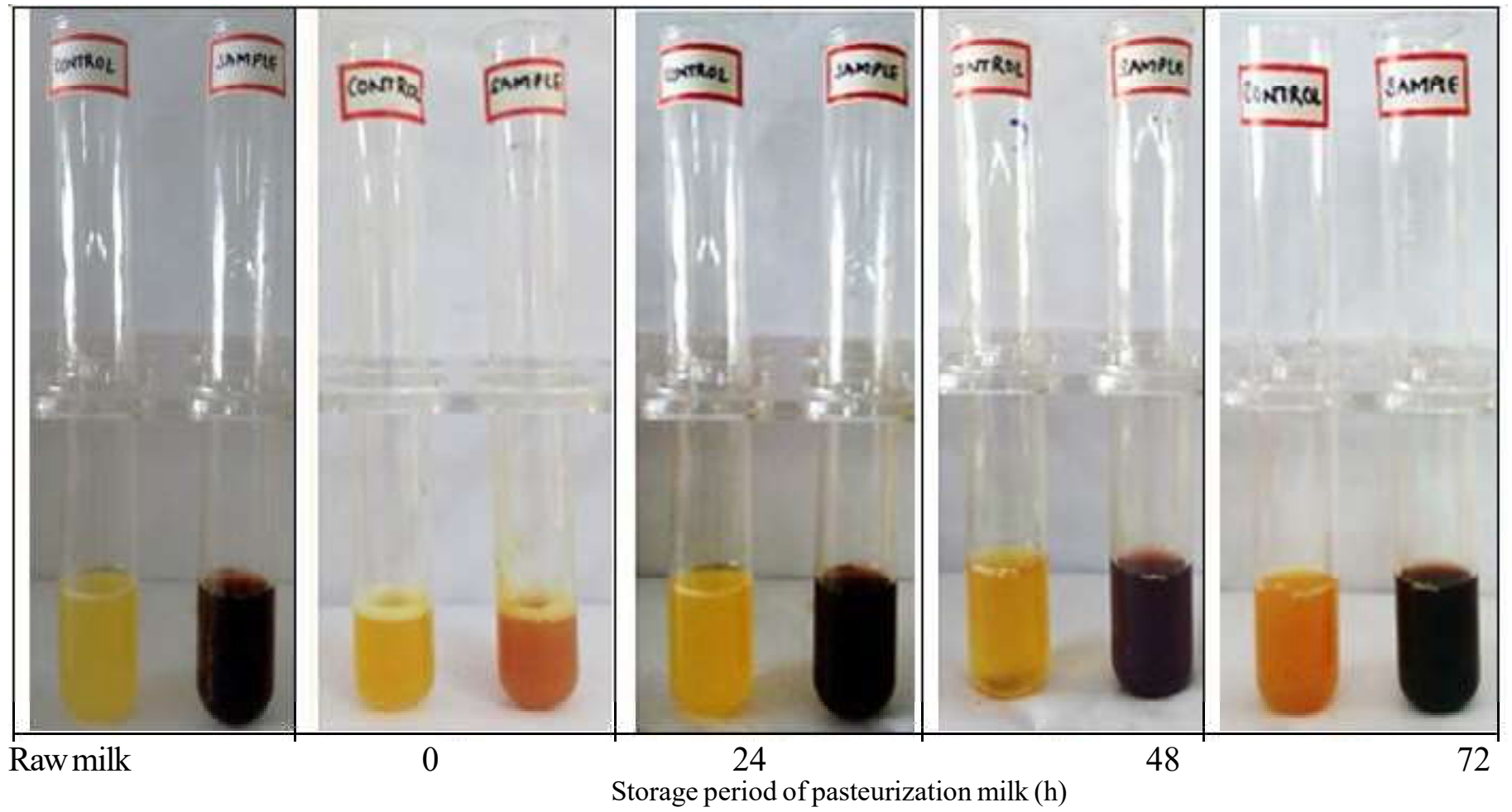

Fig. 4 Effect of pasteurization on iodine test for detection of maltodextrin in milk

In evaluation of iodine test for detection of maltodextrin in pasteurized milk and its storage at $5 \pm 1{ }^{\circ} \mathrm{C}$ for a period of $72 \mathrm{~h}$, it was observed that pasteurization had no adverse effect on performance of the test. In fact improvement in the performance of the test was noticed on pasteurization of milk as compared to raw milk. Moreover, enhancement in the performance of the test was also noticed during subsequent storage of the pasteurized milk compared to raw milk. Thus, for detection of maltodextrin iodine test can be successfully applied to fresh samples of pasteurized milk as well as samples stored at $5 \pm 1^{\circ} \mathrm{C}$ for a period of $72 \mathrm{~h}$. 


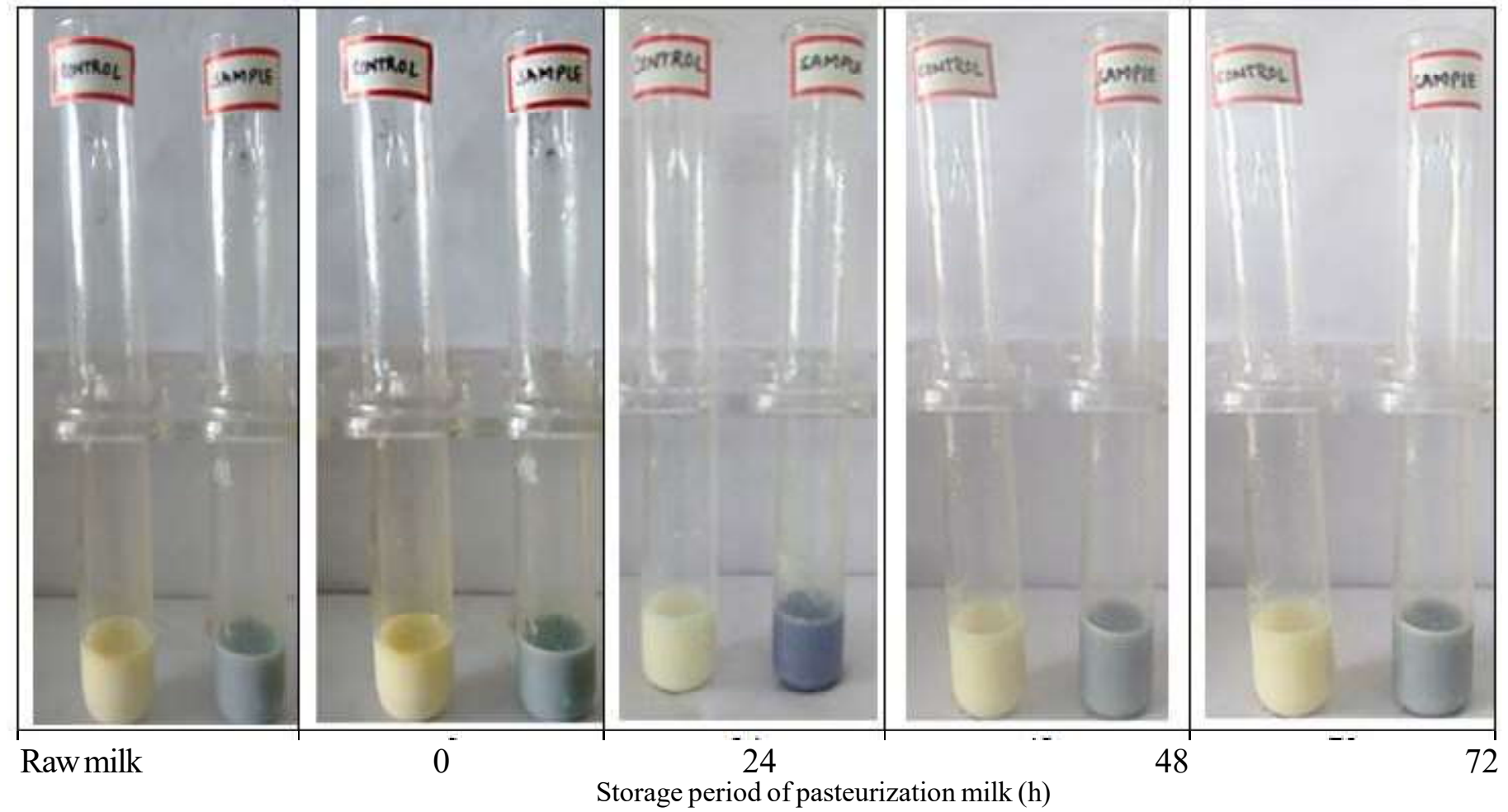

Fig. 5 Effect of pasteurization on Iodine test for detection of starch in milk

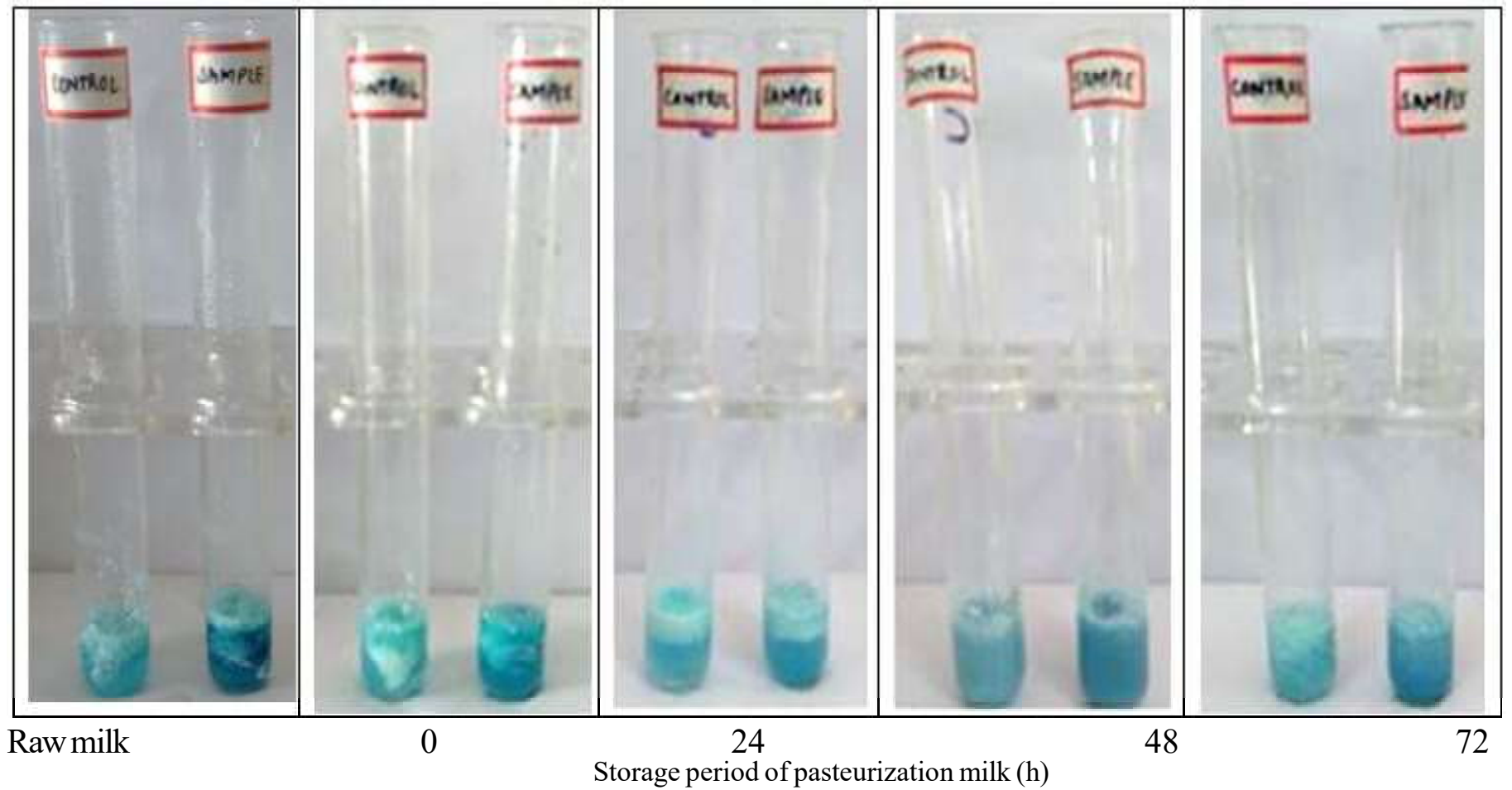

Fig.6 Effect of pasteurization om Barfoed test for detection of glucose in milk

The improvement in the performance of the test was evident from increase in intensity of red colour obtained in the test during storage of the milk samples. The improvement in performance of the iodine test for detection of maltodextrin in pasteurized milk and stored samples of pasteurized milk might be attributed to better dissolution of the maltodextrin upon heat processing and possible conjugation with whey proteins. The continuation of the solubilisation of maltodextrin and its conjugation with whey 
proteins during storage may be causing better performance of the test.

Conjugation of polysaccharides to proteins led to significant improvement in the physical or chemical properties of proteins. The conjugation of protein-polysaccharides is usually carried out by heating (de Oliveira et al. 2016). Zhu et al. (2008) studied conjugation reaction between whey protein isolate (WPI) and dextran in aqueous solutions via the initial stage of the Maillard reaction in aqueous solutions. The covalent attachment of dextran to WPI was confirmed. Because the Maillard reaction between proteins and polysaccharides in aqueous solution was slow, harsher process conditions were used to increase the yield of conjugate. The conjugation reaction was promoted by raising the temperature from 40 to $60^{\circ} \mathrm{C}$. It is expected that when the $\varepsilon$ amino groups of lysine or the $\mathrm{N}$-terminal amino group of a protein adduct to the carbonyl group on bulky polysaccharides, the Schiff base formed would be stable as a result of steric factors. The enhanced solubility and thermal stability of the conjugate was attributed to resistance to denaturation and reduced proteinprotein interactions upon glycation (Nacka et al. 1998). The views expressed by these authors very well support the findings of the present study.

\section{Effect on iodine test for detection of starch in milk}

Starch consists mainly of amylopectin and amylose, and other related fractions (Fonslick and Khan, 1989). The amylose component of starch binds with iodine to give blue colored complex (Moulay, 2013).

Neither pasteurization nor subsequent storage of pasteurized milk at $5 \pm 1^{\circ} \mathrm{C}$ for a period of $72 \mathrm{~h}$ had any adverse effect on performance of the test. Thus, for detection of starch, iodine test can be successfully applied to the pasteurized milk as well as samples subsequently stored at $5 \pm 1^{\circ} \mathrm{C}$ for a period of $72 \mathrm{~h}$.

No improvement in performance of the iodine test for detection of starch in pasteurized milk was observed, as it was noticed in case of maltodextrin detection. Such difference in performance of the test might be attributed to difference in medium used for performing the test, in maltodextrin milk serum (whey) was used as a medium to perform the test, whereas ifor starch milk was employed..

\section{Effect on Barfoed test for detection of glucose in milk}

Monosaccharides reduce $\mathrm{Cu}^{2+}$ ions to $\mathrm{Cu}^{+1}$ at higher temperatures, which is present in the form of copper acetate. The molybdenum from phosphomolybdic acid used in the Modified Barfoed's test is reduced to molybdenum blue by cuprous oxide. Thus, presence of glucose is confirmed by intense blue colour formation in the test solution (Roy and Mittal, 1977).It appears from the results that the Barfoed test for detection of glucose may be applied only to fresh samples of pasteurized milk and not during their subsequent storage. Because with the progress in storage period, the intensity of blue color in control milk sample increased gradually, which caused difficulty in differentiation between adulterated and control milk sample. In such cases the genuine samples of pasteurized milk might be interpreted as glucose adulterated sample at a later stage of the storage. Thus, Barfoed test for detection of glucose may be successfully applied to fresh samples of pasteurized milk, but not during its subsequent storage at $5 \pm 1^{\circ} \mathrm{C}$ for a period of $72 \mathrm{~h}$. The application of test in stored pasteurized milk is not recommended as interpretation of results may lead to false positive results.

Psychotropic and vegetative cells of Bacillus spp. are able to produce thermo resistant enzymes that exhibit marked biochemical activities such as hydrolysis of lactose (Samaržija et al. 2012). Moreover, bacterial activity reduces the redox potential through the consumption of available oxygen in milk and production of reducing systems in course of their metabolism (Hobbs, 1939; McCarthy and Singh, 2009). Formation of blue colour in Barfoed test for detection of glucose adulteration in milk is attributed to reduction of copper by the glucose. Therefore, development of blue colour even in control samples of pasteurized milk on storage might be attributed to formation of glucose from hydrolysis of lactose.

Effect on Seliwanoff test for detection of sucrose in milk Findings of the work suggested that Seliwanoff test for detection of sucrose was not affected by pasteurization and subsequent storage of pasteurized milk at $5 \pm 1^{\circ} \mathrm{C}$ for a period of $72 \mathrm{~h}$. In fact improvement in performance of the test was noticed during storage, as evident from increase in intensity of red colour observed in the stored samples, in comparison to corresponding fresh samples of pasteurized milk. Thus, for detection of sucrose Seliwanoff test may be successfully applied to fresh samples of pasteurized milk and also during its subsequent storage at $5 \pm 1^{\circ} \mathrm{C}$ for a period of $72 \mathrm{~h}$.

Basically Seliwanoff test is used to distinguish aldoses (e.g. glucose) and ketoses (e.g.fructose). The test works on the principle that on heating, ketoses are dehydrated faster than aldoses to hydroxymethyl furfural which then gives cherry-red or Burgundy-red coloured condensation product with resorcinol in dilute hydrochloric acid. When the test is extended to other ketoses and aldoses the same chemical deportment is observed. (Sánchez-Viesca and Góme, 2018).It is also indicated that in a dehydrated system containing sucrose and citric acid at low water activity, an appreciable browning reaction can occur due to hydrolysis of sucrose to fructose and glucose. The processing or storage of sucrose-containing foods under acidic conditions yield sufficient hydrolysis of sucrose that reactions involving reducing sugars can take place (Karel and Labuza, 1968). The fructofuranosidic linkage of sucrose is more susceptible to hydrolysis than many other glyosidic bonds. Therefore, improvement in performance of the test was noticed during 


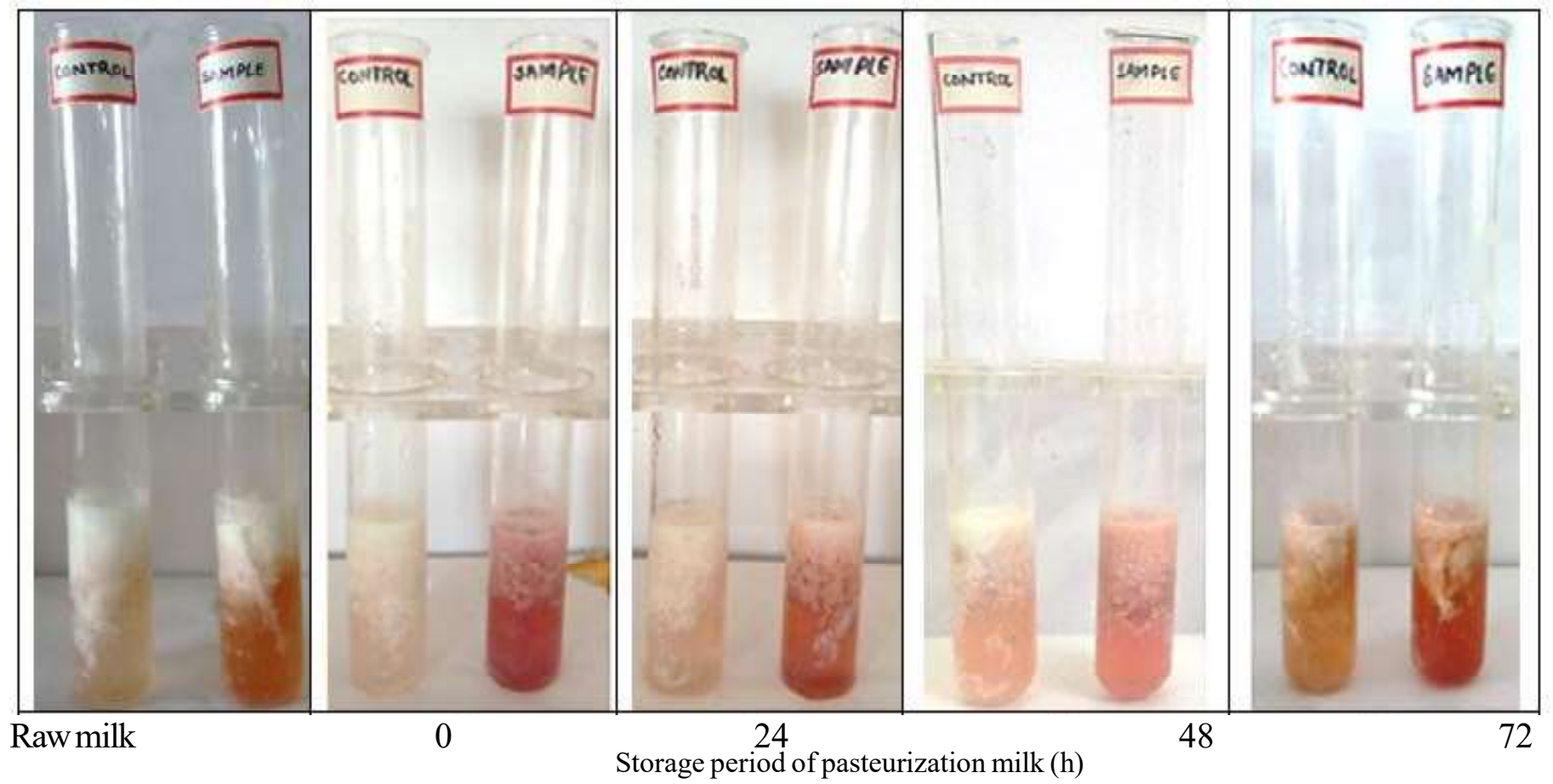

Fig.7 Effect of pasteurization on Seliwanoff test for detection of sucrose in milk

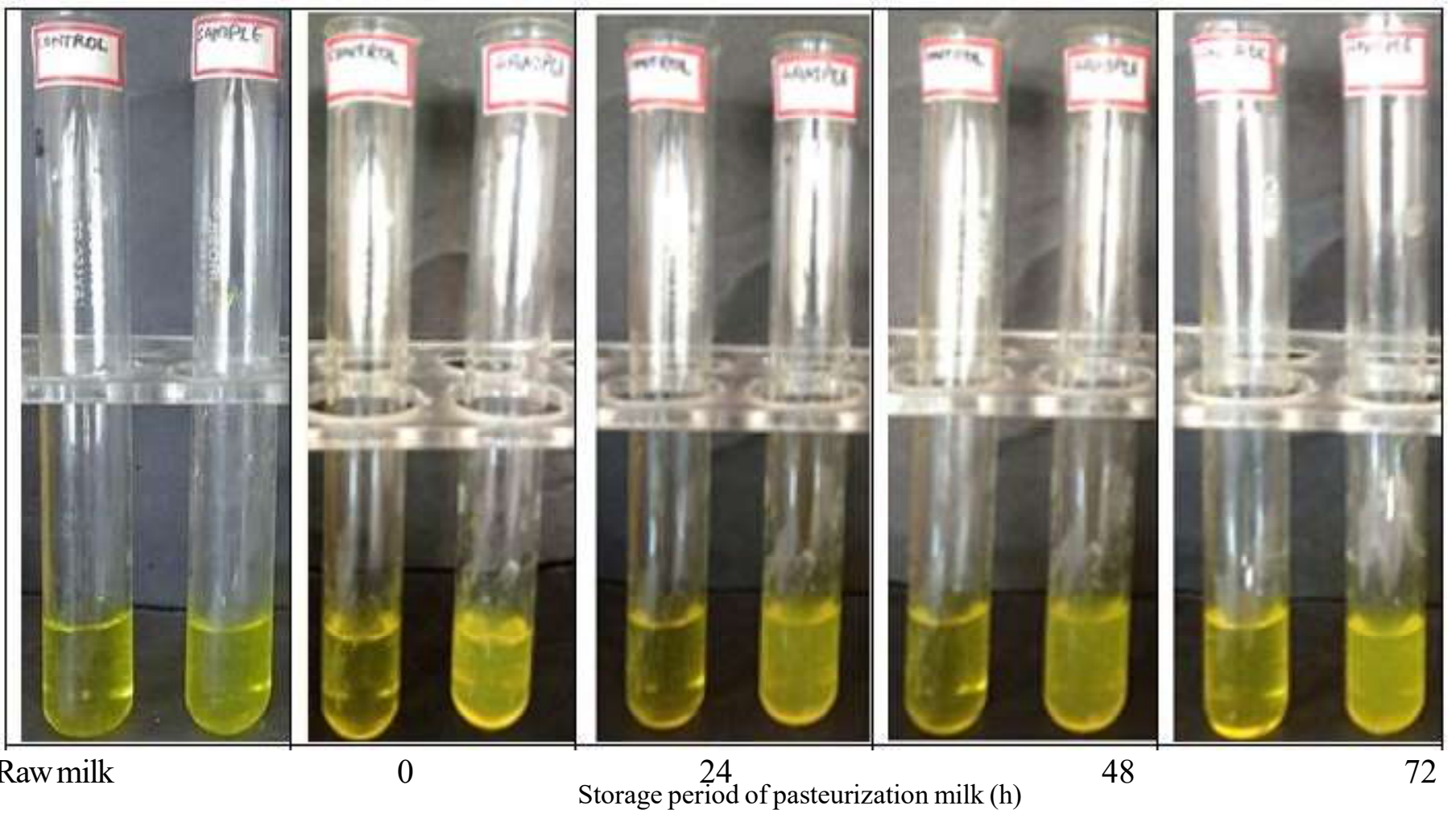

Fig. 8 Effect of pasteurization on Picric acid test for detection of gelatin in milk

storage in pasteurized milk observed in the study might be attributed to liberation of fructose from the sucrose moiety during the storage and its participation in the test.

\section{Effect on picric acid test for detection of gelatin in milk}

Both milk proteins and gelatin are negatively charged at the $\mathrm{pH}$ of milk. The positive charge on the heavy metal ion (like on 


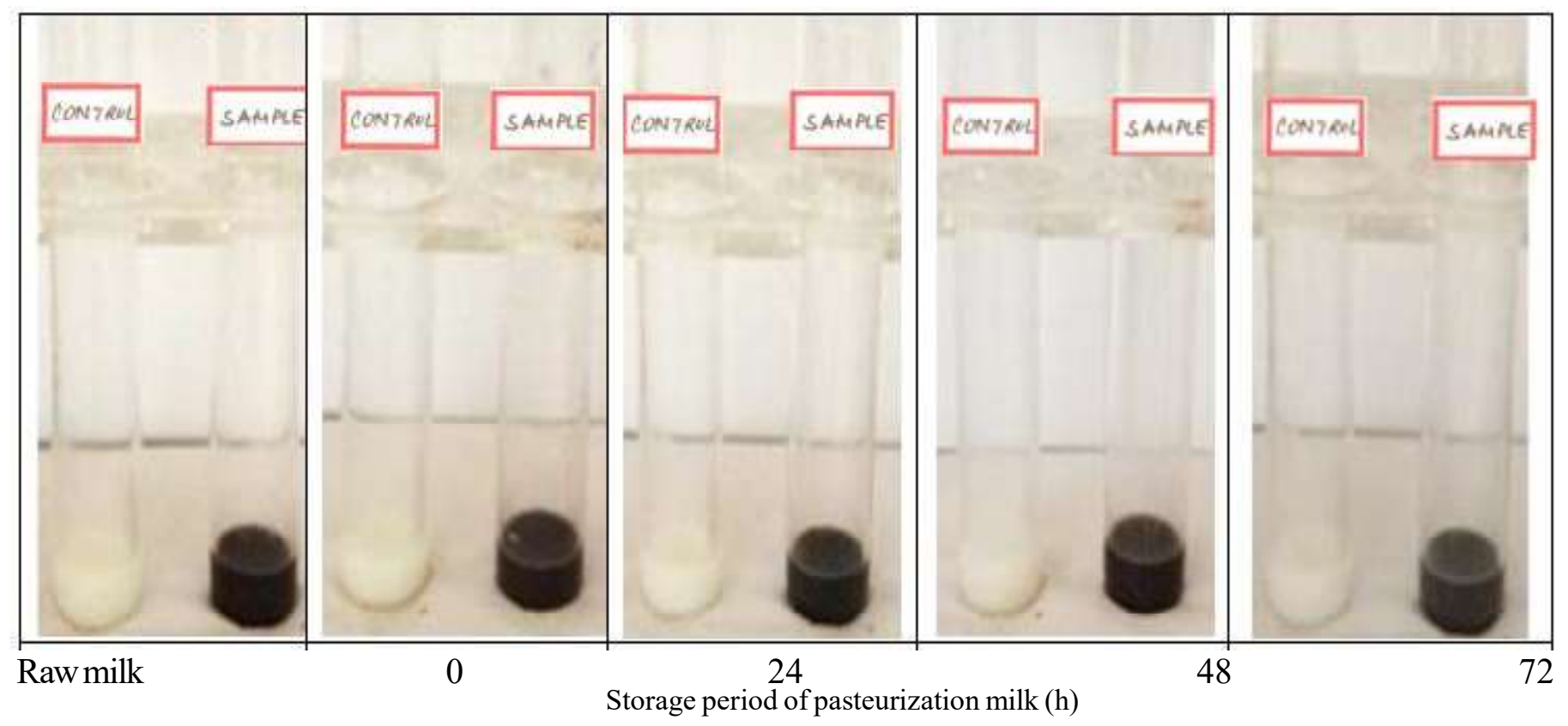

Fig. 9 Effect of pasteurization on iodine test for detection of hyderogen peroxide in milk

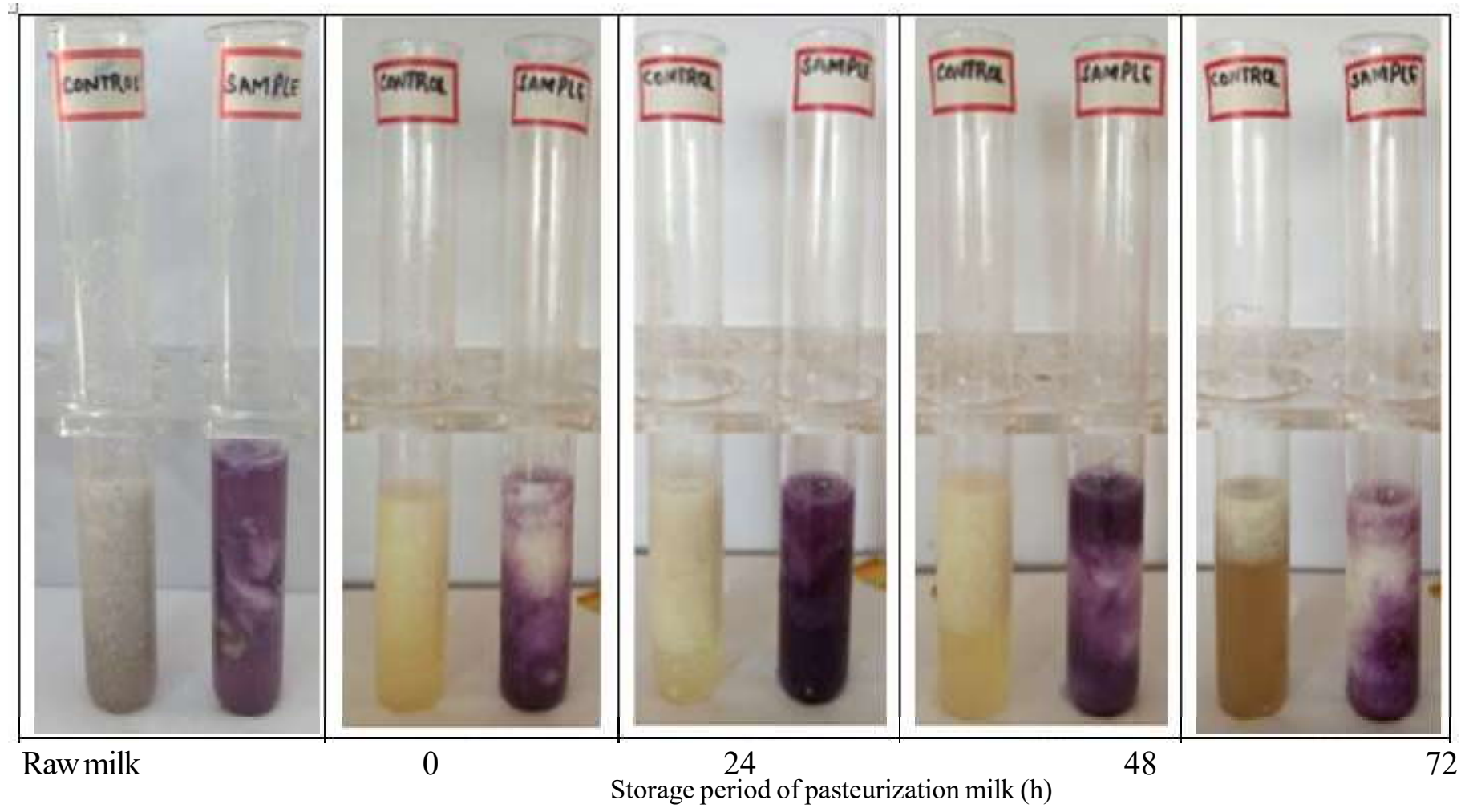

Fig.10 Effect of pasteurization on Leach test for detection of formaldeyde in milk

mercury in case of mercuric nitrate) neutralizes charge of proteins leading to precipitation. Picric acid reagent carries negative charge which can precipitate positively charged proteins (due to mercuric nitrate precipitation). The precipitate formed by picric acid are irreversible and depend on amount of gelatin present (Richardson and Tarassuk, 1934).Examination for performance of picric acid test in detection of gelatin in pasteurized milk and during its subsequent storage at $5 \pm 1^{\circ} \mathrm{C}$ for a period of $72 \mathrm{~h}$ had no adverse effect on performance of the test. In fact slight improvement in performance of the test was noticed. Thus, for detection of gelatine, picric acid test can be successfully applied to the 


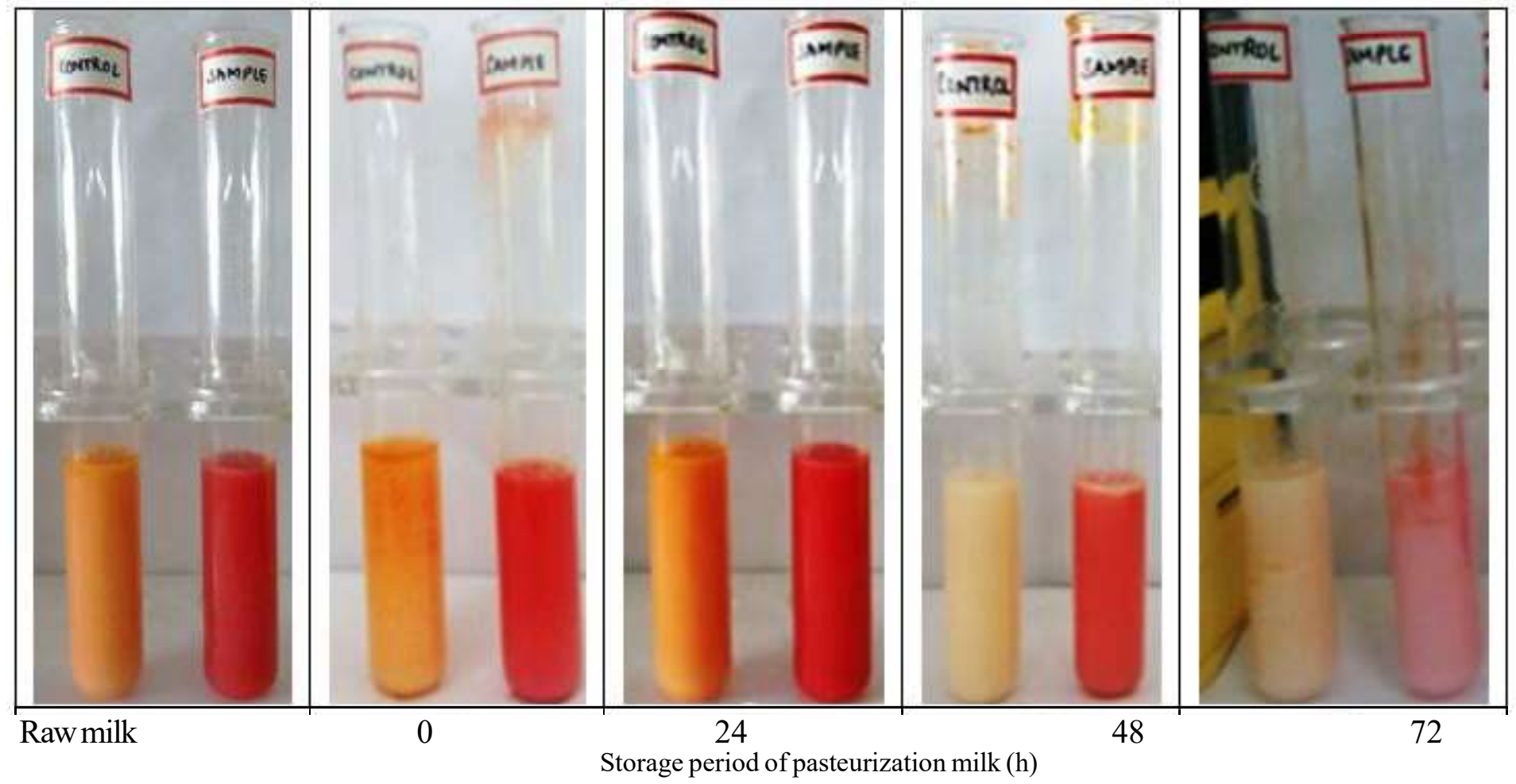

Fig. 11 Effect of pasteurization on Rosolic acid for detection of sodium hydroxide in milk

pasteurized milk and also during its subsequent storage at $5 \pm 1{ }^{\circ} \mathrm{C}$ for a period of $72 \mathrm{~h}$.

It is reported that gelatin interacts with milk protein networks as a linkages between the clusters in the products such as yogurt and acid-heat induced gels (Fiszman et al. 1999).

Gelatin is absorbed by the casein particles and which modifies their properties efficiently countering aggregation and precipitation (Cole, 2001). In a mixed protein system enhanced gel properties were observed by heating gelatin and whey protein isolate however unheated slurries were very weak at ambient temperature, (Fitzsimon et al. 2008). Therefore, improvement in performance of the test noticed during the storage of the samples in boiled milk might be attributed to heat induced interaction between gelatin and milk proteins.

\section{Effect on iodometric test for detection of hydrogen peroxide in milk}

Under acidic condition hydrogen peroxide oxidises the iodide ions to iodine. Iodine thus produced makes a complex with starch producing red, lavender to dark brown colour depending upon chain length and fraction of starch (Moulay, 2013; Saenger, 1984).

Study on effect of pasteurization of milk and its subsequent storage at $5 \pm 1{ }^{\circ} \mathrm{C}$ for a period of $72 \mathrm{~h}$ on iodometric test for detection of hydrogen peroxide suggested that neither pasteurization of milk nor its subsequent storage had any adverse effect on performance of the test. Thus, for detection of hydrogen peroxide, iodometric test can be successfully applied to the pasteurized milk and also during its subsequent storage at $5 \pm 1^{\circ} \mathrm{C}$ for a period of $72 \mathrm{~h}$.

\section{Effect on Leach test for detection of formaldehyde in milk}

In the Leach test for detection of formaldehyde in milk, concentrated hydrochloric acid and ferric chloride is used. The test is an aldehyde-oxidation reaction of an aromatic amine. Ferric chloride acts oxidising agent for formaldehyde. The formaldehyde reaction depends on the presence of the tryptophan in the protein molecule. The violet colour develops as a result of the reaction of oxidised formaldehyde with tryptophan (Low, 1907; Chrastil and Wilson, 1975).

Work carried out to check the effect of pasteurization on Leach test for detection of formaldehyde in milk revealed that neither pasteurization nor its subsequent storage at $5 \pm 1^{\circ} \mathrm{C}$ for a period of $72 \mathrm{~h} \mathrm{had}$ any adverse effect on performance of the test. Thus, for detection of formalin, Leach test may be successfully applied to fresh samples of pasteurized milk as well as samples stored at $5 \pm 1^{\circ} \mathrm{C}$ for a period of $72 \mathrm{~h}$.

\section{Effect on Rosolic acid test for detection of neutralizers in milk}

Rosolic acid is an indicator used in acid-base titrations with sharp colour change depending on the $\mathrm{pH}$ from 5 (yellow) to 6.8 (pink) (Li et al. 2008). When neutralizers are present in milk rosolic acid 
gives rose-red colour whereas pure milk shows a brownish yellow colouration due to increase in pH (FSSAI, 2016).

Effect on Rosolic acid test for detection of neutralizers in pasteurized milk and on its subsequent storage suggested that the pasteurization or is subsequent storage at $5 \pm 1^{\circ} \mathrm{C}$ for a period of $72 \mathrm{~h}$ had no adverse effect on performance of the test. Thus, for detection of neutralizers, Rosolic acid may be successfully applied to fresh samples of pasteurized milk as well as samples stored at $5 \pm 1^{\circ} \mathrm{C}$ for a period of $72 \mathrm{~h}$. Other two neutralizers (sodium carbonate and sodium bicarbonate) were also studied and results were found similar to that of sodium hydroxide. To avoid mere repetition, their Plates are not included.

\section{Conclusions}

The performance of various qualitative tests in detection of respective adulterants in fresh samples of pasteurized milk as well as samples stored at $5 \pm 1^{\circ} \mathrm{C}$ for a period of $72 \mathrm{~h}$ was evaluated. The results suggested that methylene blue test for detergent, DMAB test for urea, phenol test for ammonium salt, Seliwanoff test for sucrose, Barfoed test for glucose, iodine test for maltodextrin as well as starch, picric acid test for gelatin, iodometeric test for hydrogen peroxide, Leach test for formaldehyde and Rosolic acid test for neutralizers can be successfully applied in fresh samples of pasteurized milk and boiled milk. The tests can also be successfully applied during subsequent storage of pasteurized milk, except Barfoed test for glucose.

\section{References}

Azad T and Shoeb Ahmed S (2016) Common milk adulteration and their detection techniques. Int J Food Cont. 3 (1): 22

Bector BS, Ram M, Singhal OP (1998) Rapid platform test for the detection of added urea in milk. Indian Dairyman 50 (4): 59-62

Berg J, Tymoczko J, Stryer L (2002) Complex carbohydrates are formed by linkage of monosaccharides. In: Freeman W (ed), Biochemistry, New York

Bhatt SR, Singh A, Bhatt SM (2008) Assessment of synthetic milk exposure to children of selected population in Uttar Pradesh, India. Indian J Med Res 7:22-34

BIS (1960) Methods of test for dairy industry, Part- I: Rapid examination of milk, IS 1479, Bureau of Indian standard, Manak Bhavan, 9 Bahadur Shah Zafar Marg, New Delhi -110002.

BIS (1961) Methods of Test for Dairy Industry. Part II. Chemical Analysis of milk, IS 1479, Bureau of Indian standard Manak Bhawan, New Delhi.

Chakraborti I, Raghav SS (2000) Development of spot testing strip for determination of urea and neutralizer in milk. Asian J Chem 12(4): 1375

Chrastil J and Wilson JT (1975) A sensitive colorimetric method for formaldehyde. Anal Biochem 63(1): 202-207

Cole CGB (2001) Gelatine: its properties and its applications in dairy products. Presented at the Dairy Symposium, 7 March 2001Gordons Bay, South Africa. http://www.gelatin.co.za/dairy.htm (12-04-2018) de Oliveira FC, Coimbra JS, de Oliveira EB, Zuñiga AD and Rojas EE (2016) Food protein-polysaccharide conjugates obtained via the Maillard reaction: A review. Crit Rev Food Sci Nutr 56(7): 1108-1125

DGHS (2005) Manual of methods of analysis of foods (milk and milk products): Laboratory Manual-1. Directorate General of Health Services, Ministry of Health and Family Welfare, Government of India, New Delhi

Fiszman SM, Lluch MA and Salvador A (1999) Effect of addition of gelatin on microstructure of acidic milk gels and yoghurt and on their rheological properties. Int Dairy J 9: 895-901

Fitzsimon SM, Mulvihill DM, and Morris ER (2008) Segregative interactions between gelatin and polymerized whey protein. Food Hydrocoll 22(3): 485-491

Fonslick J, Khan A (1989) Thermal stability and composition of the amylose-iodine complex. J Poly. Sci. Part A: Poly. Chem. 27(12): 4161-4167

FSSAI (2016) Manual of Methods of Analysis of Foods: Milk and Milk Products (pp 20-21), Food Safety and Standards Authority of India, Ministry of Health and Family Welfare, Government of India: New Delhi, India

Gunnery KS (1979) Additives in milk and their detection. Ind Dairyman 31(9): 665-669

Handford C, Campbell K, Elliott C (2015) Impacts of milk fraud on food safety and nutrition with special emphasis on developing countries. Compr Rev Food Sci Food Safety 15(1): 130-142

Hobbs BC (1939) The part played by bacteria in the reduction of methylene blue in milk. J Dairy Sci 10(1): 35-58

Karel M, Labuza TP (1968) Nonenzymatic browning in model systems containing sucrose. J Agric Food Chem16: 717-719

Kimble KW, Walker JP, Finegold DN, Asher SA (2006) Progress toward the development of a point-of-care photonic crystal ammonia sensor. Anal Bioanal Chem 385: 678-685

Leach AE and Winton AL (1943) Detection of carbonate and bicarbonate of soda. In: Food Inspection and Analysis for the Use of Public Analysts, Health Officers, Sanitary Chemists and Food Economists, p. 167. New York: John Wiley and Sons

Li M, Zhang QJ, Yang JW, Tong SL, Yang KE, Xiao FS, Yan Y (2008) An efficient and simple reaction: Solvent free preparation of rosolic acid under microwave irradiation J Chem. Res. Chinese Uni. 24(3): 385-388

Low WH (1907) The test for formaldehyde in milk by Leach's modification of the hydrochloric acid and ferric chloride test. J Am Chem Soc 29 (5): 786-787

McCarthy OJ, Singh H (2009) Physico-chemical properties of milk. In: Advanced Dairy Chemistry, Vol 3: Lactose, Water, Salts and Minor Constituents. (P. McSweeney and P.F. Fox Eds.). Springer, New York, NY. pp. 691-758

Moulay S (2013) Molecular iodine/polymer complexes. J Polym Eng 33(5):389-443

Nacka F, Chobert J, Burova T, Leonil J, Haertl T(1998) Induction of new physicochemical and functional properties by the glycosylation of whey proteins. J Protein Chem 17: 495-503

Oser BL (1965) (Ed.) Hawk's Physiological Chemistry, 14 ${ }^{\text {th }}$ Ed. p. 86, McGraw Hill, Blakiston Divison, New York

Paradkar MM, Singhal RS and Kulkarni PR (2001) An approach to the detection of synthetic milk in dairy milk: 3 . Detection of vegetable oil and sodium bicarbonate. Intl J Dairy Tech 54(1): 34-35

Pedraza A, Sicilia MD, Rubio S, Pérez-Bendito D (2007) Assessment of the surfactant-dye binding degree method as an alternative to the methylene blue method for the determination of anionic surfactants in aqueous environmental samples. Analytica Chimica Acta 588: $252-260$ 
Pereira PC (2013) Milk nutritional composition and its role in human health. Nutrition 30(6): 619-627

Richardson GA, Tarassuk NP (1934) Detection of gelatin in cultured butter milk and cottage cheese. J Assoc Off Anal Chem 17: 314-319

Roy B, Singh J, Sunsunwal S, Dayal G, Yadav B, Bhardwaj C, Teotia A(2017) Detection of harmful adulterants in milk supplied to Delhi, India. Current Sci 112 (11): 2316- 2320

Roy NK, Mittal SB (1977) Rapid detection and estimation of extraneous glucose in milk and effects of the adulterant on certain physicochemical properties of buffalo milk. Ind J Dairy Sci 30(1): 30-35

Saenger, W (1984) The structure of the blue starch-iodine complex. Naturwissenschaften 71(1): 31-36

Samaržija D, Zamberlin Š, Pogačić T (2012) Psychrotrophic bacteria and milk and dairy products quality. Mljekarstvo 62(2): 77-95

Sánchez-Viesca F, Gómez R (2018) Reactivities involved in the Seliwanoff reaction. Modern Chem 6(1): 1-5
Sharma R, Rajput YS, Barui AK, Laxmana NN (2012) Detection of Adulterants in Milk-A Laboratory Manual, Edition-1. NDRI Publication No: 88/2012. National Dairy research Institute, Karnal132001

Souza SS, Cruz AG, Walter EHM, Faria JJF, Celeghini RMS, Ferreira MMC, Granato D and Santana AS (2011) Monitoring the authenticity of Brazilian UHT milk: a chemometric approach. Food Chem 124 (2): 692-695.

Srivastava MK (2010) Adulteration and detection of adulterants in milk. In: Handbook on analysis of milk - Chemical and microbiological analysis of liquid milk (pp 95-155). IBDC Publishers, Lucknow, India

Zhu D, Damodaran S, Lucey JA (2008) Formation of whey protein isolate (WPI)-dextran conjugates in aqueous solutions J Agric Food Chem 56: 7113-7118 